\title{
Hybrid Energy System with MPPT Techniques: A Review
}

\author{
Suraj Kumar \\ M. Tech. Scholar \\ Department of Electrical Engineering, Bhabha College of \\ Engineering, Bhopal, India \\ sksingh952310@gmail.com
}

\author{
Varsha Mehar \\ Assistant Professor \\ Department of Electrical Engineering, Bhabha \\ College of Engineering, Bhopal, India \\ varshamehar86@gmail.com
}

\begin{abstract}
The efficient use of energy produced from renewable energies is more important in this scenario. This document provides a detailed overview of the hybrid power system (HPS) with solar and MPPT controls. An autonomous solar system is the best choice for a rural area to provide uninterrupted energy. MPPT (Maximum Power Point Tracking) is generally used in photovoltaic (PV) systems to maximize the output power of photovoltaic panels regardless of climate change. Fast response and high tracking accuracy are two essential design requirements for MPPT control.
\end{abstract}

Keywords: Solar Panel, MPPT, PV, WT.

\section{INTRODUCTION}

Over the past decade, the oil crisis has been more acute due to economic dependence on fossil fuels. Because of this importance, the need for new energy sources is more necessary. The renewable energy source is the only solution to the problem such as pollution, which is the main reason for global warming. Since they are permanent and environmentally friendly for these reasons, research on the use of this energy has been on the rise for days. However, the technology has not yet reached its level to be considered competitive for fossil fuels. The energy analysis of solar energy, battery and diesel is discussed in this article. The main advantage of using renewable energy is the inexhaustible source of energy and the environmentally friendly nature. The main disadvantage is the lack of consistency. To overcome this drawback, it is possible to develop an autonomous hybrid system to efficiently use solar energy and also to reduce pollution caused by the diesel generator.
The use of renewable energy sources has increased rapidly over the past decade for a variety of reasons, including the decline in conventional energy sources, environmental concerns and the spread of fossil fuel prices. One of the most promising renewable energy sources are solar-based photovoltaic (PV) panels. However, due to their low efficiency and high costs, photovoltaic systems still face major challenges compared to conventional energy resources. Furthermore, photovoltaic panels are not linear.

\section{LITERATURE REVIEW}

Li $\mathrm{H}$ et al. [1] In this article, a new MPPT algorithm for total distribution (OD) is proposed, with which you can quickly search the area near the maximum global credit points. This algorithm is also integrated with the MPPT algorithm for particle swarm optimization (PSO) in order to improve the accuracy of the MPPT. Simulations and experiments demonstrate the superior efficiency and precision of the OD-PSO-MPPT algorithm proposed in photovoltaic solar systems compared to two existing MPPT algorithms for artificial intelligence.

Khan MJ et al. [2] in this document, an adaptive MPPT (Maximum Power Point Tracking) control method is proposed in order to obtain the maximum power of the wind power generation system (WT). The MPPT control method plays an important role in determining the maximum credit point and in calculating the simulation results in both analyzes, e.g. B. offline with MATLAB / SIMULINK TM and online with the OPAL-RT simulator. The proposed adaptive Perturb and Observ (P\&O) algorithm offers better results with the OPAL-RT 
simulator than the P\&O method with MATLAB / SIMULINK TM. Electricity production by a WT system with dual power induction generator (DFIG) is becoming increasingly important in the world. The result of the simulation of the OPAL-RT simulator showed that the efficiency of the WT-DFIG has been improved.

John DK et al. [3] this study consists of the analysis and modeling of an integrated flyback MPPT controlled converter for a photovoltaic system. Here, MPPT is used to maximize the power absorbed in all certain conditions, for example when the solar radiation is lower. The tracking of the maximum power point (MPPT) introduced in the photovoltaic system also follows the maximum power point that fluctuates regularly. The integrated Flyback Boost converter is used as a DC-DC converter in the proposed system. This converter combines two buckboost converters and a fly back converter in a single storey structure with a single power switch. This converter can increase the supply voltage to a higher level which can be applied for the network application.

Ali AN et al. [4] The design of two controllers is presented in this document. One is based on fuzzy logic and the other is based on artificial neural networks. Fuzzy logic controls are simple, easy to implement and do not require knowledge of the mathematical model of the system. Neural networks are known as universal approximators for nonlinear dynamic systems. Therefore, they can be used to estimate the benchmarks for maximum credit. The two controls are simulated based on variable environmental factors to examine their monitoring performance.

\section{Description OF The Hybrid System}

Wind and solar energy production depends heavily on weather conditions. This means that no energy source can provide cheap and reliable electricity [4]. The combination of renewable systems can cause electricity fluctuations. Energy storage technologies such as storage batteries (SB) can be used to reduce or even compensate for fluctuations. The correct size of the storage system depends on the location and depends on the amount of renewable energy production and the load [5]. The required storage capacity can be minimized if an appropriate combination of wind and solar energy is used for a specific location.

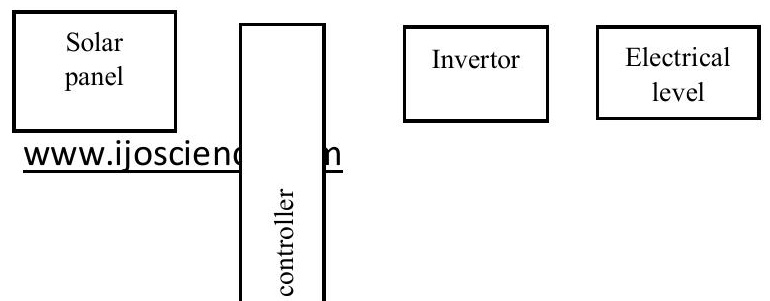

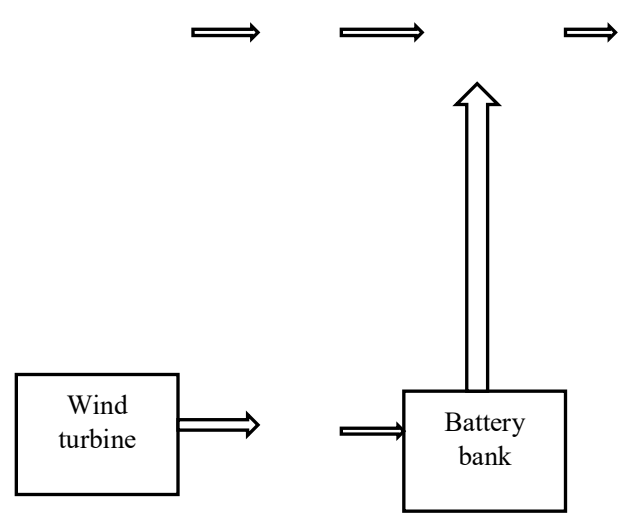

Fig. 1. Block diagram of a hybrid generation unit

\section{Maximum Power Point Tracking}

It is a DC-DC converter that increases the compatibility between a photovoltaic cell and a battery or receiver. Converts the high value DC voltage from a PV generator to the lower value voltage required at the final connection. Normally, energy conversion is never $100 \%$ and without MPPT, about $35 \%$ of energy is lost if stored in a battery. MPPT can increase this archiving process to $15 \%$ in winter and $35 \%$ in summer. Network connected systems with MPPT have a competence of $94 \%$ to $97 \%$. Although payment depends heavily on weather conditions, temperature, battery location, etc.

The Power Point Tracker is a high frequency DC / DC converter. They take the direct current input from solar modules (or alternating current from wind turbines), transform it into high frequency alternating current and convert it into another direct voltage and another direct current to adapt the modules exactly to the voltage of the network. MPPTs operate at very high audio frequencies, generally in the range of 20 to $80 \mathrm{kHz}$. The advantage of high frequency circuits is that they can be built with very high efficiency transformers and small components. The design of radio frequency circuits can be very difficult due to problems with parts of the circuit that "transmit" just like a radio transmitter that causes radio and television interference. Sound insulation and suppression become very important.

There are non-digital (i.e. linear) MPPT load controls. These are much easier and cheaper to build and design than digital ones. While they improve efficiency somewhat, overall effectiveness can vary widely - and we have seen some lose their tracking point and even get worse. This can sometimes happen when a cloud is moved 
to the panel. The linear circuit looks for the next best point, but it's too low to find it at dawn. Fortunately, there are not many left. [6]

Power point tracking technology is used in power electronics converters to convert the DC input, convert it to $\mathrm{AC}$ via a transformer (usually a toroid), then convert it back to DC through a rectifier and power the output to a regulator. Generally, MPPT is an electronic process. The microcontroller-based MPPT controllers have recently been developed to regulate battery power by observing the battery and the PV cell by adjusting their input to produce the required output voltage.

\section{MPPT TRACKING IN PV SySTEM}

The properties of the solar cell depend on solar radiation, temperature and mains voltage. Therefore, it is necessary to implement MPPT to bring the operating voltage close to the maximum power point in variable atmospheric conditions. Solar MPPT is important because it reduces the cost of solar systems by reducing the number of solar modules needed to achieve the desired performance. The V-I properties of the solar panel, in which the internal shunt resistance is neglected, are given by;

$\mathrm{I}_{0}=\mathrm{I}_{\mathrm{g}}-\mathrm{I}$ sat $[\exp \mathrm{q}(\mathrm{v}+\mathrm{Rs} * \mathrm{I}) / \mathrm{AKT}-1]$

Here A is dimensionless factor.

\section{MPPT CONTROL}

In the literature, an MPPT algorithm has been proposed to maintain a constant voltage. The maximum credit tracking algorithm is the INC method. The INC method works well in rapidly changing weather conditions. However, four sensors are required to perform the calculations. If the sensors take longer to convert, the MPPT process takes longer to trace the point of maximum power. During the tracking time, solar energy is less than the maximum power. A Buck Boost DC / DC converter is used to implement the MPPT algorithm. The $\mathrm{L}$ and $\mathrm{C}$ parameters of the step-down converter must satisfy the following conditions: The step-down converter consists of a switching device (GTO) which enables and disables based on the gate signal applied. The GTO gate signal can be obtained by comparing the saw tooth waveform with the control voltage. The basic control schemes of the inverter can be broadly divided into two categories: current control and voltage control. In a photovoltaic system connected to the grid, the inverter operates in current control mode, in which the grid regulates the voltage and frequency defining the current reference for the inverter to allow the exchange of active and reactive power. The aim is to regulate the active and reactive power on some reference values. The power and voltage references are then used to define the references of the current regulators [7]. The inverter is powered by an intermediate circuit capacitor, which is connected to an MPPT (Maximum Power Point Tracking) controller via a DC-DC converter in order to absorb maximum power from the photovoltaic system. In the mathematical model of PWM (Pulse Width Modulation), which is expressed in the rotating frame dq, there is an intrinsic coupling between the real and reactive component of the current, which makes it difficult for those who are supplied on the network from the photovoltaic generation system adjust the performance.

\section{System Control Strategy \\ A. The PV Side Control \\ The control strategy of grid connected PV inverter consists of three parts.}

a) Direct and quadrature axis current reference generator

b) PLL and d-q frame generation of grid voltage and current

c) Conversion voltage generation and PWM reference generation.

d) Fuzzy logic controller using for control MPPT of system.

The intermediate circuit voltage return and the DC reference voltage are introduced into the reference generator $\mathrm{I}_{d}-\mathrm{I}_{\mathrm{q}}$. After verifying that the unit error signal is sent to the PI controller, a reference of the $d$ axis is generated. The component of the $\mathrm{q}$ axis is reset. The mains voltage and current are then supplied to the discrete threephase PLL reference and, using the Park transformation current and the Park transformation voltage, abc are converted into d-q-o components. The conversion voltage is calculated from the generated DC reference, the measured mains voltage and the DC current reference.

\section{B. The Wind Turbine Power Control}

To control the converter on the network side, we draw two inputs. One is the reference voltage of the DC link and the other is the actual DC link voltage. The error between the two is controlled by a PI controller. Generates the current 
of the direct axis of reference on the side of the network which is compared with the current of the direct axis on the side of the real network to obtain the voltage of the direct axis on the side of the network. To minimize the cross coupling effect, additional rotation compensation terms are added, which eventually generates the voltage of the direct reference axis. In the same way, the current of the actual and reference quadrature axis on the network side is compared and controlled by a PI controller which supplies the voltage of the quadrature axis. This is added with the terms of the electromagnetic rotation compensation to generate the vector of the reference voltage of the quadrature axis. Now, the above mentioned references are used to generate the reference voltage vector for modulating the pulse width of the space vector to generate the final switching signals for this converter.

- An external DC voltage control circuit is used to set the d-axis current reference for active power control. This ensures that all the inverter from the rectifier is instantly transferred to the grid by the inverter.

- The second channel controls the reactive power by defining a current reference of the $q$ axis to a current control circuit. A voltage reference is generated for the inverter which is compensated by adding rotary EMF compensation terms.

\section{CONCLUSION}

Intensive and massive use of energy from the solar cell is of crucial importance in solving environmental problems. Implementation of the MPPT algorithm via numerical controls is simpler if the error functions can be minimized. The differences between the different MPPT techniques are very small and can be assessed according to the situation. For a particular application, choosing a particular MPPT is a difficult task and this document is a good reference for researchers working with MPPT.

\section{REFERENCES}

[1] Li H, Yang D, Su W, Lü J, Yu X “An overall distribution particle swarm optimization MPPT algorithm for photovoltaic system under partial shading". IEEE Trans Industr Electron vol. 66, issue 1, pp. 265-275, 2019.

[2] Khan MJ, Mathew L "Comparative analysis of maximum power point tracking controller for wind energy system". Int J Electron, vol. 105, issue 9, pp. 1535-1550, 2018.

[3] John DK, Davis S "Integrated fyback converter with MPPT control for photovoltaic applications ". J Embed Syst Appl, vol. 6, issue 3, pp. 1-7, 2019.

[4] Ali AN "An ANFIS based advanced MPPT control of a windsolar hybrid power generation system". Int Rev Model Simul, vol. 7, issue 4, pp. 638-643, 2014.
[5] Alabedin AZ, El-Saadany EF, Salama MMA "Maximum power point tracking for Photovoltaic systems using fuzzy logic and artifcial neural networks". In: IEEE conference on power and energy society general meeting, July 2011. pp 1-9, 2014.

[6] Hui J, Bakhshai A, Jain PK "A hybrid wind-solar energy system: a new rectifer stage topology". In: IEEE conference on applied power electronics conference and exposition (APEC), pp 155$161,2010$.

[7] Mondal A, Yuvarajan S "MPPT scheme for small scale photovoltaic systems using dSPACE". In: IEEE conference on green technologies conference, pp 1-3, 2012. 